\title{
Open Access High Throughput Drug Discovery in the Public Domain: A Mount Everest in the Making
}

\author{
Anuradha Roy, Peter R. McDonald, Sitta Sittampalam, and Rathnam Chaguturu* \\ High Throughput Screening Laboratory, Institute for Advancing Medical Innovations, University of \\ Kansas, Lawrence, KS 66047, USA
}

\begin{abstract}
High throughput screening (HTS) facilitates screening large numbers of compounds against a biochemical target of interest using validated biological or biophysical assays. In recent years, a significant number of drugs in clinical trails originated from HTS campaigns, validating HTS as a bona fide mechanism for hit finding. In the current drug discovery landscape, the pharmaceutical industry is embracing open innovation strategies with academia to maximize their research capabilities and to feed their drug discovery pipeline. The goals of academic research have therefore expanded from target identification and validation to probe discovery, chemical genomics, and compound library screening. This trend is reflected in the emergence of HTS centers in the public domain over the past decade, ranging in size from modestly equipped academic screening centers to well endowed Molecular Libraries Probe Centers Network (MLPCN) centers funded by the NIH Roadmap initiative. These centers facilitate a comprehensive approach to probe discovery in academia and utilize both classical and cutting-edge assay technologies for executing primary and secondary screening campaigns. The various facets of academic HTS centers as well as their implications on technology transfer and drug discovery are discussed, and a roadmap for successful drug discovery in the public domain is presented. New lead discovery against therapeutic targets, especially those involving the rare and neglected diseases, is indeed a Mount Everestonian size task, and requires diligent implementation of pharmaceutical industry's best practices for a successful outcome.
\end{abstract}

\section{Keywords}

High throughput screening; open innovation; drug discovery; academia; NIH Roadmap; EUOpenScreen; target identification; probe discovery; intellectual property

\section{INTRODUCTION}

The landscape for discovery of new drug targets in the post-human genome sequencing era is experiencing record growth, such is not the case for the introduction of new chemical entities (NCE) against therapeutic targets [1]. Over the last decade, the NCE introductions per year have been at nearly half the rate from the historical averages. By any account, the pharmaceutical industry is at a critical juncture at present with the research and development (R\&D) costs escalating by leaps and bounds, and the productivity, as indicated by independent new drug filings, lagging far behind. This disconnect could be attributed to the difficulty in translating the disease biology-derived therapeutic target discoveries to the

*Address correspondence to this author at the High Throughput Screening Laboratory, Institute for Advancing Medical Innovations, University of Kansas, Lawrence, KS 66047, USA; Tel: 1 (785) 864-1717; Fax: 1 (785)864-1619; rathnam@ku.edu. 
discovery and development of chemical probes and their subsequent development as preclinical candidates.

Drug repurposing, finding novel uses for old drugs, is the new 'mantra' for many pharmaceutical companies. This new endeavor infers that for many targets, there is more than one drug, and that many drugs are promiscuous, targeting more than one protein. With more than $\$ 50$ billion/year being spent on research, it is quite alarming to know that the pharmaceutical industry could not confidently affirm the selectivity and specificity of the drugs it markets. The number of US Food and Drug Administration approved drugs target less than $0.05 \%$ of the human genome, a mere 106 genes and 378 targets [2]. However, there are 4500 disease modifying genes in the human genome which include $\sim 3000$ druggable (by small molecules) genes along with another 10,000 genes that are addressable by protein therapeutics [3]. This stresses the need to critically interrogate the druggable human genome to expand the target universe, and to facilitate the discovery of new, novel and safer drugs with greater selectivity and specificity [4].

Academia has traditionally been involved in understanding the fundamental aspects of disease biology, the associated biological pathways and identifying the relevant biochemical targets for therapeutic intervention. This information has eventually led to the initiation and development of drug discovery projects within the pharmaceutical sector through its project scouting efforts either independently or licensed from the academic institution. Academia has evolved in recent years from its traditional role of target identification and validation from a systems biology perspective to probing for tool molecules (probes) against these disease targets to explore their therapeutic relevance. Probe discovery has now gained unparalleled momentum in academia with the availability of vendor-supplied, diversitybased chemical libraries, and an easy and ready access to on-campus high throughput screening (HTS) laboratories (Fig. (1)). Academic researchers, who maintain the view that HTS is an anti-intellectual endeavor, have been experiencing a change of mindset, and have come to appreciate the importance of HTS in new lead discovery and in the development of molecular probes as tool molecules. With the flow of top pharmaceutical drug discovery scientific talent into academia and the commercialization of small molecule library synthesis, academia is poised to take new lead drug discovery to greater heights. The challenge that remains to be addressed by academia is in defining the end goal of HTS. Is it just to find a 'tool' molecule, or is it to discover and develop a 'drug'? What processes and collaborations have been set in place to transform a hit to a lead? With the 'publish or perish' dogma that is embedded in academia, protection of intellectual property (IP) rights is a formidable task even if one finds the proverbial needle in a haystack. Technology transfer offices in academia continue to experience difficulty in licensing these molecular probes to pharma at very early stages of medicinal chemistry explorations. There is a heightened awareness for better understanding of the changing landscape at the pharma-academia interface, the role of academia in translational research and what constitutes a win-win scenario for technology transfer, and to strengthen opportunities for close collaboration between pharma and academia.

\section{DRUG DISCOVERY AND MARKET RISK}

All diseases occupy a position in the discovery/market risk-space that guides pharmaceutical industry's drug discovery and development endeavors. The balance between risk and reward can determine the investment and priority of a project for a given institution or company [5]. The risk of a drug discovery project can be measured by the likelihood of success, return on investment, or potential for passing clinical trials. The reward for a project is dependent on the impact of the probe against the target, or the size of the affected patient population. The market risk increases with small patient populations and decreasing financial return 
projections; and the drug discovery risk increases as targets become unconventional and uncertain. Economic considerations constrain pharma to a low risk territory and focus on proven targets in diseases with large patient populations. The dynamic between these variables and their interplay for public and private domain drug discovery projects is displayed in Fig. (2) a hypothetical generalization of the relationship between risk and reward against investment. The private domain screening campaigns tend to focus more on low risk projects against known targets, with large potential rewards, targeting diseases affecting a large percentage of the population like cancer and heart disease. The academia driven by government incentives [6], and partly by societal obligation, has stepped in to fully cover the discovery/market risk-space, as illustrated by small, upper grey dots in Fig. (2). Although the academic research on the basic and clinical aspects of orphan diseases can provide the industry with druggable targets, further labor and cost-intensive development of potential leads into drugs coupled with low market returns may not hold industry's interest in these areas. A partnership between the public, philanthropic and private sectors is viewed as a means to bring down the costs and market risks and to stimulate drug discovery in the orphan disease area.

\section{NIH ROADMAP INITIATIVE}

The complete sequencing of the human genome demonstrated that cutting-edge technologies can effectively be used in successfully addressing problems that were considered to be insurmountable just a decade ago. Using the Human Genome Project as an example, the NIH Roadmap Initiative was launched in 2005, enacted into law by Congress through the NIH Reform Act. The Roadmap Initiative sought to stimulate high-risk, interdisciplinary research facilitating translation of basic research discoveries into drugs, treatments, or methods for prevention. The NIH Molecular Libraries Roadmap [7] established three primary components toward furthering novel probe development in the public domain: (1) screening and data production, (2) data analysis and dissemination, PubChem, and (3) technology development (Fig. (3)).

The initial pilot phase of the Molecular Libraries Program (MLP), Molecular Libraries Screening Centers Network (MLSCN), consisted of ten screening centers with no significant medicinal chemistry component, and has entered into a full-fledged production phase, the Molecular Libraries Probe Production Centers Network (MLPCN), whose primary goal is to generate small molecule probes against therapeutic targets of interest by executing investigator-developed HTS campaigns, secondary and counter screens, cheminformatics, and SAR through directed medicinal chemistry efforts. The MLPCN has four comprehensive centers (NIH Chemical genomics Center (NCGC), Sanford-Burnham, Scripps and the Broad Institute), three specialized screening centers (University of New Mexico, Southern Research Institute and Johns Hopkins), and two specialized chemistry centers (Vanderbilt and University of Kansas) (Table 1). The NIH R03 application mechanism is the process by which awardees can gain access into the MLPCN program of HTS-ready assay development, screening, chem.-informatics, medicinal chemistry and probe development, all paid by the MLP. The progress of an assay to and through the MLPCN follows a critical path of steps containing cutoffs for potency, dose response, and selectivity (Table 2). The MLPCN has a library of 500,000 chemically diverse small molecules which have either known biological activities or the potential to modulate novel biological functions. The MLPCN is a pharmaceutical- industry style (and strength) drug discovery operation that is focused on new and novel therapeutic targets associated with rare and neglected diseases that are, for the most part, not being worked on by the pharmaceutical sector because of its discovery- and market-risk averse posture. Of special importance is the introduction of quantitative HTS (qHTS) paradigm, a titration-based approach that efficiently identifies biological activities in large chemical libraries. The 
traditional HTS approach tests compounds at a single concentration, and is burdened by frequent false positives and false negatives, and requires extensive follow-up testing. To alleviate this problem, NCGC has developed the qHTS paradigm [8], where every compound is tested at multiple concentrations to generate concentration-response curves, classified according to the quality of fit to the data, the number of asymptotes and response efficacy, in an efficient and cost-effective manner, and demonstrated the feasibility of qHTS for accurately profiling every compound in large chemical libraries. The qHTS approach produces rich data sets that can be immediately mined for reliable biological activities, thereby providing a platform for chemical genomics and accelerating the identification of leads for drug discovery. While the efforts at NCGC are impressive, the fact remains that high throughput screening of random/diverse chemical libraries generates null data sets since HTS is a binary modality in identifying about $99.9 \%$ inactives and $0.1 \%$ actives. The increase in concentrations of qHTS is severely cost-inhibitive, as the cost of running a qHTS campaign is at least an order of magnitude greater than the traditional HTS campaigns where compounds are tested at $\mathrm{n}=1$.

\section{PubChem}

One major benefit of the NIH Roadmap Initiative was the results sharing process, afforded through the public online database PubChem (pubchem.ncbi.nlm.nih.gov/). PubChem is an expansive database of chemical structures and their biological activities, developed by the National Center for Biotechnology Information at NIH. PubChem holds both compound information from the scientific literature as well as screening and probe data from both the MLSCN and the MLPCN, and from NIH-supported HTS campaigns carried in academia. This compound information storage platform gave new insight into compound selectivity or promiscuity, as these open access drug discovery databases provided comparative information across the hundreds of screens and bioassays to show which compounds were actives in which high throughput screens. PubChem gives researchers the ability to search bioassay records and chemical structures, and provides links to active compounds and bioassay results, as well as available biological property information for compounds. This tool brought together the results of the ten MLSCN HTS institutions, and the current MLPCN into a single, comparative system available to the public. The Pub-Chem database now lists almost 1900 HTS programs of various sizes, 1300 bioassays, over 37 million data points against 171 molecular targets. ChEMBLdb, the European counterpart of the PubChem, lists 2.4 million records, and provides information on the properties and activities of over half a million drugs and drug-like molecules and their targets. The NIH roadmap initiatives along with the MLSCN-/MLPCN programs have identified over 93 probes with submicromolar potency, which amounts to be approximately $\$ 6.2$ million per probe, illustrating the enormous difficulty in identifying probes against novel therapeutic targets (Table 3) [9]. One could also attribute this to the inefficiency in coordinating therapeutic biology with medicinal chemistry, a rare combination of skills in the biomedical science community which is more biology-oriented.

\section{Eu-OpenScreen}

One of the most ambitious open access high throughput drug discovery platforms in the public domain, EU-Open-Screen, an European counterpart for United States' NIH Roadmap initiative, is being coordinated by Dr. Ronald Frank, Leibniz-Institut für Molekulare Pharmakologie, Berlin, Germany, under the auspices of the Capacities Programme of the European Commission (www.eu-opens-creende). It is open to all European organizations involved in Chemical Biology, and the current participation includes a total of 19 academic and non-profit institutions from 17 European countries, and brings together biomedical scientists representing all related and required disciplines. This will be an association of HTS centers across Europe, and offers resources for executing high throughput screens for 
hit discovery and optimization, bio-and chemoinformatics support, and a publicly accessible database, analogous to PubChem, the latter providing screening results, assay protocols and chemical information. The chemical library, representing the chemical knowledge of Europe, will be housed in a central location. The Eu-OpenScreen, a transnational venture and much broader in scope than the NIH Roadmap initiative, will provide European researchers access to the most advanced screening technologies and support projects on unconventional targets that address fundamental biological questions in all disciplines of Life Sciences. A much thought out framework for IP management is integral to the EuOpen-Screen operational infrastructure, thus ensuring rapid knowledge sharing and commercial exploitation of gained knowledge.

\section{ACADEMIC HTS CORE FACILITIES}

Within the past few years, academia has jumped into the arena of probe discovery in a rather big way, and started setting up medium and high throughput core screening facilities with needed instrumentation and expertise, which used to be the forte of the pharmaceutical industry enterprise [10]. A number of key factors have influenced this transformation, including the availability and price of compound libraries, equipment, and technology. For libraries, there is a wide array of vendor-supplied, high quality, diverse chemical libraries. In addition to decreasing prices for libraries, the market has seen a maturation of automation equipment including liquid handlers and laboratory robotics, screening and signal detection technology platforms including reagents and instrumentation. Most importantly, there is a flow of pharmaceutical industry talent into academia, aided by the huge lay offs undertaken by pharma in its desperate cost cutting ventures to boost its profitability margins [11]. Dedicated academic HTS centers are equipped with compound libraries on the order of 100,000 compounds or greater, and possess a variety of 96/384-tip liquid handlers, bulk liquid dispensers, and multi-format plate readers (Table 4). These HTS labs have the capacity to address multiple assay methodologies [12]. Public domain screening efforts are limited to medium or high throughput, with the exception of the NCGC, an ultra high throughput screening (uHTS) center. The NCGC uses a Kalypsys High-Throughput Robotic Screening System to perform ultra high throughput screens in 1536-well format, pushing throughput up to a million wells/day.

Unfortunately, the NIH Roadmap Initiative supports its own network centers with no support provided to the other HTS centers in academia. This is reflected by the fact that most academic HTS facilities, compared to those in the pharmaceutical industry or NCGC, suffer immensely from a lack of public funding. Academic HTS is also hindered by a lack of integrated robotic screening platforms, and compound collections are modest with no institutional medicinal chemistry collections being part of the chemical library holdings. Further, academic HTS data analysis software tends to be home-grown and strewn together by open source programs and lack the sophistication needed in carrying comprehensive data analysis routines.

While most academic HTS core facilities are for exclusive use by its own institutional investigators, some institutions (for e.g. the University of Kansas) have broadened their reach by opening the doors to investigators from institutions, both public and private, where a state-of-the-art HTS infrastructure may not be available [13]. While these core facilities are primarily a fee-for-service operation, the main goal of these facilities is to see the investigators succeed in their probe discovery endeavors, and for which they contribute intellectually above and beyond what was originally conceived in setting up these facilities [14]. 
Drug discovery research is often termed as searching for a needle in a haystack. Large compound libraries, corporate chemical archive databases, virtual compound collections and chemical library supplier's databases are routinely screened, either in the laboratory or in silico, for drug candidates. This endeavor is worse than finding a needle in a haystack, as we do not exactly know the size or shape of the needle. We have very limited knowledge about the chemical probe, the needle, that we need to find. Often we do not know how it looks or even if it is there or not. However, there is a distinct possibility that we may end up finding more than one. After exhaustively picking all of the low hanging fruits, the pharmaceutical industry has invested heavily in HTS technologies and the robotic platforms to screen millions of compounds, both corporate as well as vendor-supplied collections. Although academia has increasingly ventured into the arena of HTS, its end goal remains undefined beyond publications and garnering extramural funding. In academia, not MLPCN, the involvement of medicinal chemistry in taking screen hits to the level of bona fide probes still remains at large. The concept of medicinal chemistry as an unbroken continuum of HTS efforts, as has long been the case in pharmaceutical industry, stills needs to be anchored into the mindset of academia.

\section{Target Identification}

The human genomic sequence is being probed in academia and industry using genomics, proteomics, small interfering RNA (siRNA) and mouse knockout models for identification and validation of disease-relevant targets $[4,15,16]$. The strength of the academic investigators lies in target identification, validation and elucidating the mechanistic aspects of therapeutic drug targets, and it is primarily done in the investigator's own laboratory. While it is perceived that academic investigators conduct cutting edge research, it is all too common that they do not necessarily employ cutting edge tools in driving their research because of budget limitations, sheer lack of interest, or knowledge. If academia wants to explore the large repertoire of undrugged targets in the most efficient manner, the principal investigator (PI) should partner with the HTS facilities in designing innovative assays towards target identification and validation, as well as to screen these novel targets which can be used in discovering bona fide probes. For instance, academic investigators can effectively take advantage of increasingly affordable and commercially available human and mouse genome-wide siRNA libraries toward target identification using institutional HTS labs. In addition, several smaller siRNA sub-libraries are also available for screening at various HTS centers. The University of Texas Southwestern Cancer Center HTS Laboratory allows the academicians to perform high-throughput screening of genomic siRNA libraries. The HTS Bioscience center at Stanford university has siRNA screening sets divided into GPCR (517 genes), kinase (779), drug-gable genome (6022), and the remaining genome $(13,804)$ for a total of 21,122 targeted genes (http://htbc.stanford.edu/htmolbio/sirna.html). The genes identified in HTS experiments are potential novel targets [17] for compound screens leading to probe discovery.

\section{Screening Technologies}

The successful completion and execution of drug discovery projects require the alignment of the capabilities of the HTS center with that of the incoming projects. The HTS center interacts with technologists, chemists and biologists to develop more productive screening projects. The academic screens encompass a wide variety of targets and associated assay formats, and the academic HTS centers are equipped with a wide range of detection systems, such as luminescence, fluorescence, FLIPR, FRET, absorbance, ELISA, microscopy-based imaging, and small molecule microarray (Table 5). There are many academic centers that focus on one or more specialized technologies. The ability to perform miniaturized biological assays in 384-well and 1536-well format is no longer limited to the private sector. Public domain HTS centers have many of the same capabilities and technologies as pharma, 
enabling equal capacity for pre-screen basic research, elaborate secondary and tertiary screening, and the ability to elucidate mechanism of action (MOA). These capabilities cover a wide range of biologies including enzyme targets, GPCRs, ion channels, transporters, protein-protein interactions, protein misfolding and protein degradation. The ability to address MOA and tertiary screens are handled easily by public domain through a diverse set of screening platform technologies, including high content screening (HCS), highthroughput microscopy and high content analysis (HCA), flow cytometry, HTS and ultra HTS, NMR-based methods, and access to BSL-3 level laboratories.

Several screening centers have taken extra measures to stand out and have developed novel screening platforms. For example, the University of New Mexico Center for Molecular Discovery is a specialty screening center focusing on multiplexed, high throughput flow cytometry approach to identification of small molecules that bind to cellular receptors and modulate clinically therapeutic cellular responses. The center has a customized screening platform called HyperCyt which enables sampling throughput rates of 40 samples per minute [18] for the measurement of particle fluorescence at the single-cell level. The technique is very sensitive, allowing real-time detection of 10-100 pM fluorescent molecules on a cell or a bead. The assays are homogeneous and do not require wash steps since the laser excites a very small volume surrounding the cell and limits the excitation of unbound fluorescent molecules.

Public domain HTS centers are the focal points for familiarizing the new technology-shy academic investigators with breakthrough technologies, yet very few embrace label-free (cell-based and cell-free) assay formats and other very powerful technology platforms. Currently, the majority of the HTS assays rely on labels of some sort (luminescent, fluorescent or radioactive) to monitor cellular responses and to quantify biochemical reactions. Conventional label and reporter-based cell assays are often prone to artifacts due to perturbation of the native cellular environment, either by the label or by over-expression of the target or the reporter protein. The labels can have adverse effects on binding interactions, leading to false or misleading conclusions about binding properties of screening hits. For this reason, label-free technologies are especially ideally suited for use with cellbased screening or hit-to-lead optimization platforms.

Label free detection platforms, such as Corning's Epic, Sru Biosystems' Bind and Roche Biosciences' xCelligence systems, can serve important roles in primary screening as well as lead optimization, and should be seriously considered in academic settings. Many cellular processes including proliferation, migration, adhesion and apoptosis are associated with very specific and well-defined changes in cell morphology and adhesion. All of these changes are measured by the label-free technologies utilize the biophysical properties to generate a quantitative functional output for various cellular outcomes including cytotoxicity, receptormediated signaling, cell migration, cell adhesion, etc. These techniques alleviate the need for cellular labeling or over-expression of reporter proteins, and allow real-time kinetic measurements in native and physiologically relevant cell environment. The label-free technologies can measure changes in impedance as cell grow in plates armed with goldelectrodes (Roche's xCELLigence system) or can measure changes in refractive index (Corning's Epic) [19]. Some technologies utilize acoustic or fiber-optics to measure changes in cell morphology or size. The label-free technologies can be fairly flexible and therefore allow for rapid assay optimization and development. In primary screenings, label-free technologies reduce the number of false positives or false negatives. In lead characterization stages, the dynamic monitoring of cellular events can be used to obtain signature patterns or profiles for compounds with similar mechanisms in long-term cytotoxicity assays. Surface plasmon resonance (SPR) technology is another powerful label-free technology platform for monitoring interactions between low-molecular-weight molecules and target proteins [20]. 
The binding affinity measurements from SPR can be used for hit identification and profiling when working with targets of unknown function or in the absence of a functional assay. SPR technology therefore has a place in both primary screenings as well as lead characterization stages of high throughput drug discovery campaigns.

Protein-protein interactions, stable or transient, are at the core of almost every metabolic pathway, and in cellular responses to extracellular signals. As such, it is an area of great interest for therapeutic intervention. Protein-protein interactions between an antibody and antigen have been used successfully in development of biologics that are highly specific and efficacious. Despite their high costs of production, the biologics comprise a major share of the market and are currently used in treatment of cancer, immune disorders, etc. The major challenge in obtaining orally available, small molecule drug-like compounds lies in defining surfaces and residues involved in intracellular protein-protein interactions [21, 22]. In vast majority of cases, designing small molecules to antagonize interactions at the hot spots specifically is very challenging and requires knowledge of stoichiometry, binding sites, number of interaction partners and fluidity of interacting surfaces. The yeast two-hybrid system is one of the most popular techniques available for identifying protein-protein interactions in vivo. Enzyme-linked immunosorbent assays (ELISAs), fluorescence polarization (FP), and SPR have also been applied in a HTS mode for the identification of small molecule modulators of protein-protein interactions, albeit with much less success. AlphaScreen ${ }^{\circledR}$ and AlphaLISA ${ }^{\circledR}$ are powerful reagent platforms that utilize Perkin Elmer's proprietary bead-based Alpha technology can be applied in HTS mode to screen for proteinprotein interaction modulators [23]. Multiangle, time-dependent, static light scattering is a powerful technology platform for probing and identifying small molecules that affect protein-protein interactions without the need for labeling, immobilization, substrates, cofactors, etc. Because of the therapeutic relevance of this important area, academic HTS laboratories can make important contribution by evaluating and eventually embracing the most robust technology formats that is HTS amenable.

Advances in automated microscopy hardware and image acquisition and analysis software have led to a boom in high throughput microscopy [24], and their incorporation into cellbased screens to produce high content screening (HCS). By automating the process of image capture and analysis, HCS can be applied to hundreds of microtiter plates, enabling the automated analysis of millions of individual cells in tens of thousands of samples, to fit the high throughput microscopic analysis needs of drug discovery and systems cell biology. The prevalence of fluorophores and labeled antibodies, biosensors, and environmentally sensitive probes and stains, fluorescence microscopy can be applied through high content analysis (HCA) to many drug target classes. HCS can be applied with multiple filter sets and confocal microscope capacities, allowing simultaneous multiple target readouts, or multiplexing, and can provide subpopulation analysis on groups of uniquely affected cells in a larger population. Thus the "content" of high content screening refers to the wide amount of multi-parameter quantitative and qualitative information collected, as compared to single parameter target data of standard biochemical and cell-based high throughput screen. The multiplexing aspect of HCS allows researchers to study both the target effect of a primary screen while collecting data for tertiary effects for elucidating the MOA of a compound [25].

\section{Importance of Secondary Screens}

While academia has made great strides in implementing HTS campaigns for hit finding, the relative importance of secondary screens in affirming selectivity and specificity of the primary screen actives has not been given a fair share or a serious consideration as a continuum of the front end of the probe discovery effort. The hit to lead optimization efforts aim to turn this overwhelmingly large and varied collection of molecules into a manageable number of compounds which can serve as starting points for the lead optimization process 
[26]. The process involves subjecting each molecule to a series of robust and rapid secondary assays to assess compounds for lead-like properties and identify ones that have a high likelihood of success in pre-clinical and clinical phases of drug development. The secondary screens ought to include counter-assays that address cytotoxicity, permeability and metabolic stability, such as HERG inhibition, Caco-2 permeability, CypP450 inhibition and virtual screenings. Identification of meaningful assays that help establish a direct relationship between the target and the compound activity are vital to the success of hit to probe to lead identification and optimization. These counter-assays are designed to ensure that significant time and effort is not wasted on chemotypes with intrinsic liabilities at later stages of lead optimization.

\section{Grant Application Support}

An important aspect of the function of HTS core facilities is to support PIs in their efforts to garner extramural funding. An obligatory function of the HTS staff is to provide letters of support that outline a strategic approach for choosing assay design specifics. HTS staff also performs assay development, generating quality preliminary data with acceptable statistical parameters, and draft necessary secondary and counter screens to ascertain selectivity and specificity. The HTS staff collaborates in submitting PIs grant applications geared towards NIH Roadmap initiative supported R21 (PAR-08-024) mechanism- assay development (not HTS ready) for high throughput molecular screening (http://grants.nih.gov/grants/guide/pafiles/PAR-08-024.html), R03 (PAR-09-129) mechanism-development of assays which are screening ready and implementation in one of the MLPCN centers, (http://grants.nih.gov/ grants/guide/pa-files/PAR-09-129.html), and Fast Track Entry (NOT-RM-09-011) mechanism by bootstrapping an existing $R 21$ that is ready for screening, or an R01 which has some type of screening context in the application for screening in one of the MLPCN centers (http://grants.nih.gov/grants/guide/notice-files/NOT-RM-09-011.html). In addition to these NIH sponsored granting mechanism, HTS staff is actively involved in supporting a number of other funding opportunities including those from non-NIH governmental agencies and not-for-profit disease foundations. It is to the benefit of the PI to make the application a relatively strong one by having HTS staff as Co-PIs or collaborators. Pre-grant mentoring is another important function of the HTS staff as well. This would include advice on 1) deciding between an R01, R03, or R21 submission, 2) opting for core facilities on a fee-for-service basis, 3) cutting edge tools and assay formats for formatting investigator's bench-top assay for the high-throughput environment, and 4) the amount of preliminary data required.

\section{Improving Science through HTS Consultation}

A typical public screening center commonly receives dozens of requests for screening collaborations. However, many of these collaborations are from labs with no experience with the stringent quality control requirements of HTS, and often, there are new assay systems that may be more ammenable to HTS but not known to the investigator (Fig. (4)). The collaboration of a PI with an HTS lab can lead to a positive outcome as science is improved through consultation. A recent client of the KU-HTS core proposed a multistep lactate dehydrogenase (LDH) assay in a 12-well plate format for a cell-based screening project. The HTS lab miniaturized the assay down to 384-well format, cutting well size by $1 / 32$ and cutting costs by decreasing reagent use. Consultation with the HTS lab revealed that an alternative assay system would be more prudent for the client's work. Upon studying the science related to the cell biology being tested, the measurement of cytotoxicity or viability would be equally important for evaluating compound efficacy. The HTS lab then compared five different assays head-to-head simultaneously to determine which assay was more suitable for a client's HTS needs: (1) a heterogeneous cell viability assessment, (2) a heterogeneous absorbance-based LDH assay, (3) a homogenous absorbance-based LDH 
assay, (4) a fluorescent cytotoxicity assay, or (5) a luminescence cyto-toxicity assay. The homogenous assays proved to be more suitable for HTS than the client's multistep heterogeneous assay. The cell viability assay was also able to inversely measure cytotoxicity by the remaining cells, as directly compared to the client's cytotoxicity assay. The simplicity of the homogenous cell viability assay allowed for dramatically fewer handling steps, allowing the procedure to be miniaturized to 384-well and automated using bulk liquid dispensers and robotic automated liquid handling instruments.

\section{Strengthening Public Domain HTS through Industry Best Practice}

Industry has spent decades learning the best ways to increase output through teamwork among multiple research cores, towards a single common goal. In recent years, academia has moved away from the individualistic approach of prior generations toward this same interdisciplinary approach. The KU HTS lab plays an active role in applying industry best practice to its collaborations, due to experienced project mentorship. The HTS director and project managers have many years of experience in the pharmaceutical industry, and commandeer teamwork to unify efforts across multiple labs and cores. This management was recently applied on a project spanning 20 cancer cells lines from 5 different research groups, using at least four different assay methods to measure efficacy of potential anticancer compounds. To evaluate a novel panel of compound analogs, the project management team consulted with the lead investigators from each research group and decided on a key assay platform that would accommodate each investigator's needs. The compound panels were evaluated using a homogenous cell viability assay using newly purchased cell lines from ATCC in a miniaturized 384-well plate format. Rather than use cell lines from individual labs, the cell lines were purchased from ATCC to follow MTA agreements with ATCC. This assured the origin and handling of each cell line, and avoided potential problems that occur from long-term passaging of cells, such as contamination with other cell lines (contaminating cell lines with Hela cells), and to prevent importing mycoplasma or other contaminants from the collaborating labs. A quantitative ATP assay was used to replace the various labs' methods of quantifying cell viability and cytotoxicity, in a manner that allowed 384-well format miniaturization and assay automation. The investigators agreed that the ATP assay was more suitable to the high throughput measurement of cell viability due to its sensitivity, simplicity, speed, flexibility, and signal stability. The entire panel of cell lines was cell banked, and optimal seeding density was determined for each to assure assay uniformity from cell line to cell line. The cytotoxicity of the analogs was determined at multiple concentrations using the panel of 20 cell lines. The results of the studies enabled the rank ordering of each compound for cytotoxicity in multiple cell lines in parallel. The cell growth inhibition data revealed both the most potent compounds and the most sensitive cell lines. The mutual agreement across labs for a unified HTS project applied to a wide assortment of assay conditions and cell lines provided comparable data across the cell lines. This project was heavily dependent on strong, industry-style management.

\section{HTS Data Management}

The pharmaceutical industry has expended enormous amount of resources, both in manpower and software, towards data storage, analysis, and management. In addition to the experimental data, the data management system handles information on chemical library, stocks management, compounds and their molecular structures and descriptors, and allows efficient structure similarity searches against internal or commercial libraries. In the early days of screening, home-grown software ruled the day. But in the past few years, vendor solutions have become more robust, giving organizations viable alternatives to building and maintaining systems themselves [27]. A number of commercially available data management systems like the Pipeline Pilot scientific data workflow platform (Accelrys) 
and Activity base XE (IDBS) enable custom data processing applications. Many of the databases can be queried using accessory modules provided by Spotfire or MDL systems. To achieve successful integration of metadata for all compounds and to provide a context or direction to assist medicinal chemists and others with interpreting and acting on screening results, pharma is partnering with software companies to customize software for consolidating data from isolated databases. Such partnerships are seen in Amgen Lead Discovery Informatics between Amgen and Genedata, which allows integration of voluminous data from Amgen's screens and the Next-Gen Discovery IT between Tripos and Wyeth (now Pfizer), have a patented method of characterizing the structural diversity of large combinatorial libraries with information located in their disparate databases.

While large pharmaceutical companies and well-endowed establishments can afford highend oracle-based sophisticated data management tools, most universities and institutes rely on alternative measures for data storage and management. Many HTS centers have developed their own data management systems utilizing the services of their affiliated information technology services. The M-screen at University of Michigan and K-Screen at University of Kansas are examples of indigenous data management systems, but these neither have the requisite sophistication, speed or breadth needed in managing HTS data, and to allow timely comparison of activity profiles across screens. The NIH Roadmap supported comprehensive screening centers including NCGC employ sophisticated data analysis tools, and a mechanism needs to be developed and instituted to bring up to speed their brethren in the rest of the academia.

\section{Probe Discovery and Development in Academia}

The word "probe" is a broad term which can be interpreted to mean any one of a wide variety of agents. These include active chemistries discovered in academic screening labs or in government (MLPCN or the NCGC), commercially available probes (i.e. dyes, antibodies, fluorescent proteins), failed drug candidates from pharma, whole body or cellular imaging agents, specific biomarkers or tool molecules from chemigenomics and/or systems biology efforts. The probes are designed to interact with the biological (biochemical) target of interest rather selectively and help explore the role of the target in a systems biology context. A high quality probe is expected to have proven chemical identity, highly potent with selectivity and submicromolar affinity towards the target in vitro, efficacious, a sigmoidal dose-activity relationship within two orders of the tested concentration range with $\mathrm{nH}=1$, best in series with a reasonable set of congeners to develop QSAR profiles suggestive of target selectivity, and be functionally active in a cellular system (minimally) to link target biology with disease biology under study. It is not necessarily be drug-like, adhere to Lipinski rule of 5 principles, clear ADME/T profile, or have a clear path to IP rights. Likewise, probes are not to be confused with those identified from a systems biology approach including those that are active in high content or phenotypic assays where integrated pathways are interrogated. In our opinion, a bona fide probe has to be either specific or selective at the biochemical target level (Table 6).

The success of any high throughput screening campaign in finding a target-specific probe is dependent to a large extent on the assay design and on the quality of the chemical library. While the assay design is target-specific and the academic investigator has invested his/her lifetime in this arena, the chemical libraries at the academic HTS centers, without exception, have been assembled from commercial sources and are modest in size. The compound libraries are typically composed of purchased, screen-friendly, library sets such as the LOPAC (Sigma), ChemBridge Corp. (San Diego, CA), Prestwick (Illkirch, France), MicroSource (Gaylordsville, CT), and ChemDiv, Inc. (San Diego, CA). Despite the fact that many FDA approved drugs like erythromycin, paclitaxel and doxorubicin were derived from 
natural products, and that almost 50\% out of the 877 small-molecule New Chemical Entities (NCEs) introduced between 1981 and 2002, were natural products or their analogues, there has been no significant interest within the academic HTS centers to include natural product libraries as part of their chemical archives.

The end goal of the HTS efforts in academia and the unprecedented investment by the US Federal Government through the NIH Roadmap Initiative is to find bona fide probes against disease relevant drug targets. The question that still remains to be answered, rather critically, is whether academia has the ability, both infrastructure-wise as well as commitment-wise, to reach the end goal, above and beyond the acquisition of grant funding, publications, and the holistic exercise of HTS. By any measure, the jury is still out in rendering its verdict. From the pharmaceutical industry perspective, the front end of drug discovery requires an interdisciplinary approach involving molecular biologists, cell biologists, biochemists with HTS ready assay development experience, specialists in automation, robust data analysis and cheminformatics tools, molecular modelers, medicinal chemists, and project coordinators to bring the key players from all the disciplines together to facilitate informed go or no-go decisions on a project in the most efficient way. This concept of integrated, matrix-team oriented collaborative effort is almost foreign to much of academia. To make drug discovery in academia a reality, we desperately need the pharmaceutical industry's best practice to make drug discovery in academia a reality. Institutions such as the Institute for Advancing medical Innovations at University of Kansas and the Pennsylvania Center for Drug Discovery, have taken a lead in this regard. The IAMI has implemented pharmaceutical industry's best practices to identify, advance and commercialize IP, and has created a highly collaborative, entrepreneurial environment which attracts other academic institutions, industry and disease-focused non-profit organizations into partnership with the KU.

Industrialization of chemical library synthesis has revolutionized the HTS concept with the vendor-supplied chemical libraries forming the backbone of academia's drug discovery efforts. While institutional chemistries are the jewels of pharmaceutical HTS operations, the legacy compounds from the institutional medicinal chemistry departments seldom progress to the chemical archives of the academic HTS centers. One of the most disconcerting aspects of HTS operations in academia is the inefficiency in coordinating therapeutic biology with medicinal chemistry, a rare combination of skills in the biomedical science community which is more biology-oriented. In fact, of the two dozen academic HTS centers in the United States, only three have institutional medicinal chemistry departments (University of Kansas, University of Minnesota, and University of Pittsburgh). The University of Kansas benefits from an integrated medicinal chemistry core to help support the probe discovery efforts. In the absence of concerted medicinal chemistry involvement, the academic HTS operations are rather an exercise in futility, which was apparent in the MLSCN phase of the NIH Roadmap initiative where there was minimal medicinal chemistry involvement. Contrary to the situation in academia, the HTS operations in pharma are designed and destined for success as random library screening is actively supported with focused libraries as well as iterative synthetic support by experienced medicinal chemistry teams. For HTS operations in academia to be successful, we need the pharmaceutical industry's best practice of sourcing as well as optimization of the chemistry.

Medicinal chemistry involvement at an early stage of drug discovery is essential since the screen actives, in general, are neither selective not potent against the therapeutic target, and requires iterative synthesis efforts to bring forth an increase in potency by 2 to 3 orders of magnitude, and a plethora of counter/secondary screens to navigate the synthesis efforts in achieving target site selectivity [28]. For the academic drug discovery initiatives to succeed, expert medicinal chemistry is therefore critical. There are 143 well defined substituents 
reported in the literature. If we use all of them in just three positions, we would have 1,433 or 2,924,207 possible compounds. An experienced medicinal chemist might consider making a drastic structural change, based on historical perspective, prior hands-on knowledge, and cheminformatics. It is in this area that the academic drug discovery programs are at their weakest due to lack of adequate medicinal chemistry support. The drug discovery and development initiatives at academic institutions such as University of Kansas and the Pennsylvania Center for Drug Discovery present a unique model for fostering a matrix team approach. This approach is based on a pharmaceutical industry-based best practice, bridging the gap between in vitro drug target screening and chemical probe development so as to make drug discovery in academia a reality.

\section{Open Innovation in Lead Discovery}

Using the paradigm 'a problem shared is a problem solved', open innovation has taken a strong hold within the last few years in reinvigorating the pharmaceutical R\&D endeavors. This is a shift from 'innovation within the corporate walls' concept to the acquisition of IP from outside the corporate walls to advance its business models, a concept that literally admits as well as advocates the fact that a problem shared is a problem solved. Pharmaceutical companies have traditionally safeguarded their own interests and eliminated competition by stringent IP protection. With the goal of speeding innovative drug discovery by tapping into global wealth of knowledge and expertise, big pharma is opening up information flow to public domain and is aggressively establishing new R\&D structures to foster open-innovation strategies up with academia [29]. Such collaborations are advantageous to both academia and industry. Academia and universities receive more research dollars for innovative projects, greater involvement for faculty in drug discovery process as well as a secure path to product development and licensing processes. Pharma gains novel and relevant targets to feed its pipeline as well as new molecular probes for lead optimization processes [30]. As shown in Table 7, some such collaborations include Novartis Institutes for biomedical Research to discover and develop drugs for a range of inadequately treated diseases, GSK's Centre of Excellence for external drug discovery, Pfizer's Biotherapeutics and Bioinnovation Center, Lilly Melbourne Academic Psychiatry Initiative for advancing mental health research and education in Australia, and a \$14 million investment by Pfizer at the University of California (Santa Barbara, CA), Caltech, MIT and University of Massachusetts and Entelos, a physiological modeling company, to re-examine the regulatory mechanisms of human energy metabolism, and hence expand the understanding diabetes and obesity pathobiology. Merck has created a virtual department, External Basic Research, to foster partnerships with academic and biotech collaborators to identify and access novel targets, using a shared risk paradigm to deliver preclinical candidates for its pipeline. Burnham is collaborating with $\mathrm{J} \& \mathrm{~J}$ on a multi-year assay development and licensing deal by granting exclusive access to its high-throughput assay screening technologies, in order to determine potential targets for new drugs against inflame-matory diseases, such as arthritis and lupus. $\mathrm{J} \& \mathrm{~J}$ has also established two partnership-focused units to ensure the continued nurturing of early academic research (COSAT) and facilitate translational or applied research toward drug development (eRED). Together, J\&J and academia have a unique opportunity to create an enduring partnership that will accelerate the introduction of innovative medicines. One of the most impressive open access drug discovery partnerships was by UK's Wellcome Trust through a 5-year Seeding Drug Discovery Initiative (SDDI) in 2005 to facilitate the discovery and development of drug leads to fill the unmet medical need gap. It has awarded over $\$ 135$ million to 30 institutions supporting 30 drug discovery projects, and has resulted in access to recognized experts in the field, dozen patents and three candidates in various stages of clinical trials. The partnership complemented the lack of pharmaceutical expertise of the academic investtigators by providing project management oversight, and provided enormous 
cost savings as there was no need to develop infrastructure for each of the novel drug targets. A recent review of the SDDI program has indicated the academic collaborators' lack of medicinal chemistry experience to be a major gap, thus confirming our assertion that biomedical researchers tend to me more biology-oriented, and that coordinating therapeutic biology with medicinal chemistry in academia requires an efficient matchmaking by experienced project coordinators, an Industry best practice.

Open innovations also include Lilly's Phenotypic Drug Discovery Initiative (https:// pd2.lilly.com/pd2web), in which the compounds synthesized in academia are screened against phenotypic and other relevant assays optimized in Eli Lilly. While Lilly provides all evaluations and data free of charge and both the investigator/institution retains IP rights to the molecule, with Lilly seeking first rights for IP licensing and/or refusal. Merck has created SAGE, an open access, non-profit, organization to bring academia and pharma together to develop comprehensive human disease biology models, and provided vast database of highly consistent data about the biology of disease and software tools to use it. The open innovation strategy was also adopted by GSK which has removed its IP restrictions for promoting research in the area of neglected diseases like malaria. GSK has made available 13,500 malaria compounds for open research. GSK has also released genomic \& protein expression profiling data for over 300 cancer cell lines via the NCI's cancer Bioinformatics Grid ${ }^{\mathrm{TM}}$ for academia to mine. To fully explore the potential of drug repurposing, a pharma-academia integration effort was launched through CTSA Pharmaceutical Assets Portal. It now includes 350 researchers from a number of pharmaceutical companies (Pfizer, Merck, GSK, Novartis, Genentech, Abbott, Eli Lilly, AstraZeneca) and 45 universities including University of California Davis, Oregon H\&S University, University of Washington, University of Pennsylvania, and the University of Chicago probing 150 disease targets.

In addition to these, a number of multimillion dollar investments have been made by the pharmaceutical giants at a number of academic institutions (GSK-Harvard, \$50 million Pfizer-University of California, $\$ 9.5$ million, Pfizer and University of Pennsylvania, $\$ 15$ million, to further the basic understanding of systems biology pathways related to human diseases. These open innovation models is a strategic paradigm shift in overcoming pharma's long held NIH, "Not Invented Here" syndrome [30], and the realization that the task at hand is too large for any one institution, and the collective wisdom of academia and pharma is critical to combat human diseases and suffering.

\section{Protection of Intellectual Property}

One of the fundamental tenets of academic research is that the results are to further scientific knowledge by publishing in peer reviewed journals. Until the 1980s, the government owned intellectual property (IP) from federally funded research, and this research went into public domain in the form of publications and presentations without IP rights. This inhibited the industry from immediately transforming the research ideas coming out of academia into marketable products. The passage of Bayh-Dole Patent and Trademark Act of 1980 was intended to promote comercialization of inventions resulting from federally funded research. This act provided an incentive to the inventors to use patents to protect their IP. Offices of technology transfer were soon created widely across academic institutions, followed by an increase in patent applications from federally-funded research. Technology transfer offices continue to assist in the commercialization of research results funded primarily by the government for the welfare of the public. Tasks required by this role include the preparation of confidentiality agreements, materials-transfer agreements, licensing out technology, examining IP, and collaborative agreements with industry. The technology transfer from academia to industry entails pre-discovery data sharing, experimental data for testing computational compound prediction and pharmacological models. An increase in academic/ 
industry relationship is also reflected in establishment and success of the Association of University Technology Managers (AUTM). The AUTM reported an increase in scientific patents issued to universities from 890 to 2120 in the post-Bayh-Dole decade. Under the auspices of the National Science Foundation, Kauffman Foundation, University of Illinois and others, the University-Industry Demonstration Partnership (UIDP) program was launched in 2006 to nourish and expand collaborative partnerships between university and industry in the United States. The UIDP has developed Turbo Negotiator, a software tool, to guide both sides to agreement on nature of project. India's Academia Industry Interaction Project is along the same vein, and has created a National database to promote and facilitate pharmaceutical research through government-academia-industry partnership.

With regards to the results coming out of the academic HTS labs including those of the MLSCN/MLPCN, the IP may lie in the use but not in the composition of matter. This is because the majority of chemical libraries used by academic HTS labs are in the public domain. Even though the MLPCN is inching more towards a dedicated chemistry-driven effort in following up with the screen actives with IP potential, the NIH Roadmap initiative mandates that the research results of the sponsored research be deposited in the public domain through PubChem, with at best a 6 month hold on public disclosure. This does not give enough time to fully explore the chemistry around the putative probe to make it commercially attractive. Furthermore, most academic technology transfer offices are unable to extract the IP potential of research coming out of the academic labs, and may not have the experience or the necessary tools to prose-cute and defend IP rights. Many times, the academic investigator approaches pharma to gain access to a tool compound for use in his/ her research and signs a Material Transfer Agreement with terminology such as, "recipient hereby grants to the company a non-exclusive, worldwide, royalty-free, paid-up license, with the right to sublicense, under any patent or other IP rights covering any use of any of the Materials or derivatives arising from Requester's research there with". The academic investigator should be aware of ironclad clauses like this which would permanently exclude them from reaping the benefits of their research. Another classic example of academia's IP inexperience is exemplified by COX-2 story. The University of Rochester School of Medicine and Dentistry published and filed for a patent in 1992 where in it claimed for the usefulness of a COX-2 inhibitor in pain management. The same year, Merck and Searle launched COX-2 programs and launched hugely profitable Celebrex and Vioxx in 1998. The University filed a suit against Searle (Pfizer) in the year 2000, but eventually lost in the US Supreme Court "because the inventors here simply failed to take the last critical step of actually isolating a compound, or even developing a process through which one of skill would be directly led to such a compound, this patent involves 'little more than a research plan"” the court concluded. This illustrates the fact of not to rush to patent prematurely, and this requires effective guidance from a well experienced technology transfer office. For spinoff and incubator companies around academic innovations, careful thought must be given at the outset whether to license a technology or product, or build a company around it. Given that $95-97 \%$ of projects result in no licensable IP, the technology transfer offices have an incredible responsibility in navigating academic research into a profitable enterprise.

\section{A Roadmap for Successful Drug Discovery in Academia}

The stochastic nature of screening for probes is now a recognized discipline in academia. Each of the academic screening centers, with different specializations, has the potential to develop to a level of maturity and robustness to contribute meaningfully towards development of chemical probes in the era of chemical genomics. In the pharmaceutical sector, new lead discovery has transformed over the years from being an art into a robust scientific discipline. Having spent a collective number of decades in the pharmaceutical sector, our perspective on drug discovery in academia is a mix of apprehension and 
appreciation. Academia's endeavor in the arena of drug discovery is a Mount Everest in the making, and requires careful nurturing to make it a successful reality (Table 8).

The core strength of academia is in basic and mechanistic biology, and the drug discovery efforts need to be built on this solid platform. Pharmaceutical industry's best practice of matrix-based multidisciplinary team approach should be implemented in the public sector. This approach should formulate the project goals and milestones by laying out a critical project management path with industry-experienced project managers. It is important to convey the message that the PI is in driver's seat and seek strong, healthy collaborations. At the very outset, draft target hypothesis and validation criteria, HTS assay design, validation, readiness and implementation, active-hit-lead definitions, data analysis routines, secondary and counter screens to address selectivity and pharmacokinetic issues, and work towards a collaborative venture. A workstation-based, state-of-the-art screening facility should be established with pharma-trained personnel. Personnel from the PI's lab should be made part of the project team in transferring and validating the bench-top assays into the HTS lab. This is a critical step in the assay transfer process, because the PI's bench-top assay may not be as adequately robust or reproducible enough for the stringency of HTS. Since the success of any HTS campaign in finding a target-specific probe is dependent on the assay design and on the quality of the chemical library, best possible assay design should be favored over what has been developed at the origination lab, and a high quality diverse chemical library should be used. Institutional chemistries are equivalent of the corporate crown jewels. Every possible effort should therefore be made to add the institution's own legacy chemistries into the HTS chemical archives by advocating the novelty and uniqueness of these chemistries, therapeutic relevance, and the value of serendipity in finding the unexpected. This could be achieved by emphasizing the fact that any IP that comes out from testing the institutional chemistries lies with the PI who made the compounds. Because of the suspect authenticity and the quality of the cell lines used in the PI's lab, it is strongly advocated that cell lines for use in cell-based assays be purchased from commercial sources. If commercial sources are unavailable, it is important to ascertain the imported cell lines are not contaminated, using a quarantine cell-culture lab. An experienced medicinal chemist's intuition is critical for the success of any probe discovery endeavor, and a competent medicinal chemist either from one's own institution or a collaborating institution must be recruited early on to carry data mining, to ascertain chemical tractability and early SAR by commerce or synthesis. The personnel from the technology transfer and commercialization office must be brought into the project as soon as the target hypothesis has been drafted to ensure that the IP rights are adequately clarified, protected and nurtured. For the probe discovery and development initiatives in academia to be successful, the projects need to be actively managed, to prevent an exercise in futility. New lead discovery against therapeutic targets, especially those involving the rare and neglected diseases, is indeed a Mount Everestonian size task, and requires diligent implementation of pharmaceutical industry's best practices for a successful outcome.

\section{Acknowledgments}

The authors would like to thank Drs. Scott Weir, Roy Jensen, Barbara Timmermann, Joseph Heppert and George Wilson for their vision in promoting drug discovery research initiatives at KU, and their commitment to the HTS laboratory's research priorities. KU-HTSL is a KU Cancer Center Shared Resource, and is funded in part by NIH/ NCRR COBRE grant P20 RR015563.

\section{REFRENCES}

1. Munos B. Lessons from 60 years of pharmaceutical innovation. Nat. Rev. Drug Discov. 2009; 8(12):959-968. [PubMed: 19949401] 
2. Overington JP, Al-Lazikani B, Hopkins AL. How many drug targets are there? Nat. Rev. Drug Discov. 2006; 5(12):993-996. [PubMed: 17139284]

3. Hopkins AL, Groom CR. The druggable genome. Nat. Rev. Drug Discov. 2002; 1(9):727-730. [PubMed: 12209152]

4. Sakharkar MK, Sakharkar KR. Targetability of human disease genes. Curr. Drug Discov. Technol. 2007; 4(1):48-58. [PubMed: 17630928]

5. Knowles J, Gromo G. A guide to drug discovery: Target selection in drug discovery. Nat. Rev. Drug Discov. 2003; 2(1):63-69. [PubMed: 12509760]

6. Wellman-Labadie O, Zhou Y. The US Orphan Drug Act: Rare disease research stimulator or commercial opportunity? Health Policy. 2009; 24:24.

7. Austin CP, Brady LS, Insel TR, Collins FS. NIH molecular libraries initiative. Science. 2004; 306(5699):1138-1139. [PubMed: 15542455]

8. Inglese J, Johnson RL, Simeonov A, Xia M, Zheng W, Austin CP, Auld DS. High-throughput screening assays for the identification of chemical probes. Nat. Chem. Biol. 2007; 3(8):466-479. [PubMed: 17637779]

9. Oprea TI, Bologa CG, Boyer S, Curpan RF, Glen RC, Hopkins AL, Lipinski CA, Marshall GR, Martin YC, Ostopovici-Halip L, Rishton G, Ursu O, Vaz RJ, Waller C, Waldmann H, Sklar LA. A crowdsourcing evaluation of the NIH chemical probes. Nat. Chem. Biol. 2009; 5(7):441-447. [PubMed: 19536101]

10. Gordon EJ. Small-molecule screening: it takes a village. ACS Chem. Biol. 2007; 2(1):9-16. [PubMed: 17243777]

11. Frantz S. How academia can help drug discovery. Nat. Rev. Drug Discov. 2004; 3:541. [PubMed: 15272492]

12. Frearson JA, Collie IT. HTS and hit finding in academia - from chemical genomics to drug discovery. Drug Discov. Today. 2009; 14(23-24):1150-1158. [PubMed: 19793546]

13. McDonald P, Roy A, Taylor B, Price A, Sittampalam S, Weir S, Chaguturu R. High throughput screening in academia: Drug discovery initiatives at the university of kansas. Drug Discov. World. 2008; 9(4):59-74.

14. Frye, S.; JanZen, B. Discovering Academia. 2007. p. 1-4.www.FuturePharmaUS.com

15. Lindsay MA. Target discovery. Nat. Rev. Drug Discov. 2003; 2(10):831-838. [PubMed: 14526386]

16. Austin CP. The impact of the completed human genome sequence on the development of novel therapeutics for human disease. Annu. Rev. Med. 2004; 55:1-13. [PubMed: 14746506]

17. Quon K, Kassner PD. RNA interference screening for the discovery of oncology targets. Expert. Opin. Ther. Targets. 2009; 13(9):1027-1035. [PubMed: 19650760]

18. Sklar LA, Carter MB, Edwards BS. Flow cytometry for drug discovery, receptor pharmacology and high-throughput screening. Curr. Opin. Pharmacol. 2007; 7(5):527-534. [PubMed: 17652026]

19. Xi B, Yu N, Wang X, Xu X, Abassi YA. The application of cell-based label-free technology in drug discovery. Biotechnol. J. 2008; 3(4):484-495. [PubMed: 18412175]

20. Lausted C, Hu Z, Hood L, Campbell CT. SPR imaging for high throughput, label-free interaction analysis. Comb. Chem. High Throughput. Screen. 2009; 12(8):741-751. [PubMed: 19531009]

21. Arkin MR, Wells JA. Small-molecule inhibitors of protein-protein interactions: progressing towards the dream. Nat. Rev. Drug Discov. 2004; 3(4):301-317. [PubMed: 15060526]

22. Sundberg EJ, Mariuzza RA. Luxury accommodations: the expanding role of structural plasticity in protein-protein interactions. Structure. 2000; 8(7):R137-R142. [PubMed: 10903952]

23. Taouji S, Dahan S, Bosse R, Chevet E. Current screens based on the alphaScreen technology for deciphering cell signalling pathways. Curr. Genomics. 2009; 10(2):93-101. [PubMed: 19794881]

24. Denner PS, chmalowsky J, Prechtl S. High-content analysis in preclinical drug discovery. Comb. Chem. High Throughput. Screen. 2008; 11(3):216-230. [PubMed: 18336214]

25. Korn K, Krausz E. Cell-based high-content screening of small-molecule libraries. Curr. Opin. Chem. Biol. 2007; 11(5):503-510. [PubMed: 17931958] 
26. Roy, A.; Taylor, B.; McDonald, P.; Price, A.; Chaguturu, R. Hit-to-Probe-to-Lead Optimization Strategies: A Biology Perspective to Conquer the Valley of Death, in. In: Seethala, R.; Zang, L., editors. Handbook of Drug Screening. Informa Healthcare; 2009. p. 21-55.

27. Ausman DJ. Screening's age of insecurity. Modern Drug Discov. 2001; 4(5):32-34.

28. Lombardino JG, Lowe JA 3rd. The role of the medicinal chemist in drug discovery--then and now. Nat. Rev. Drug Discov. 2004; 3(10):853-862. [PubMed: 15459676]

29. Gray NS. Drug discovery through industry-academic partnerships. Nat. Chem. Biol. 2006; 2(12): 649-653. [PubMed: 17108976]

30. Hunter J, Stephens S. Is open innovation the way forward for big pharma? Nat. Rev. Drug Discov. 2010; 9:87-88. 


\section{Academic research}

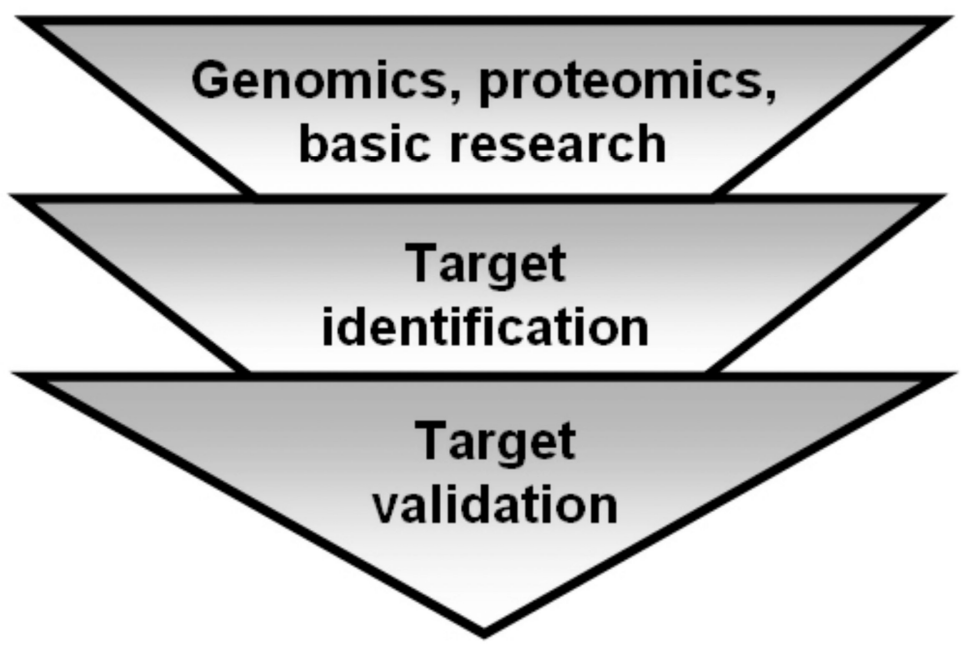

HTS research

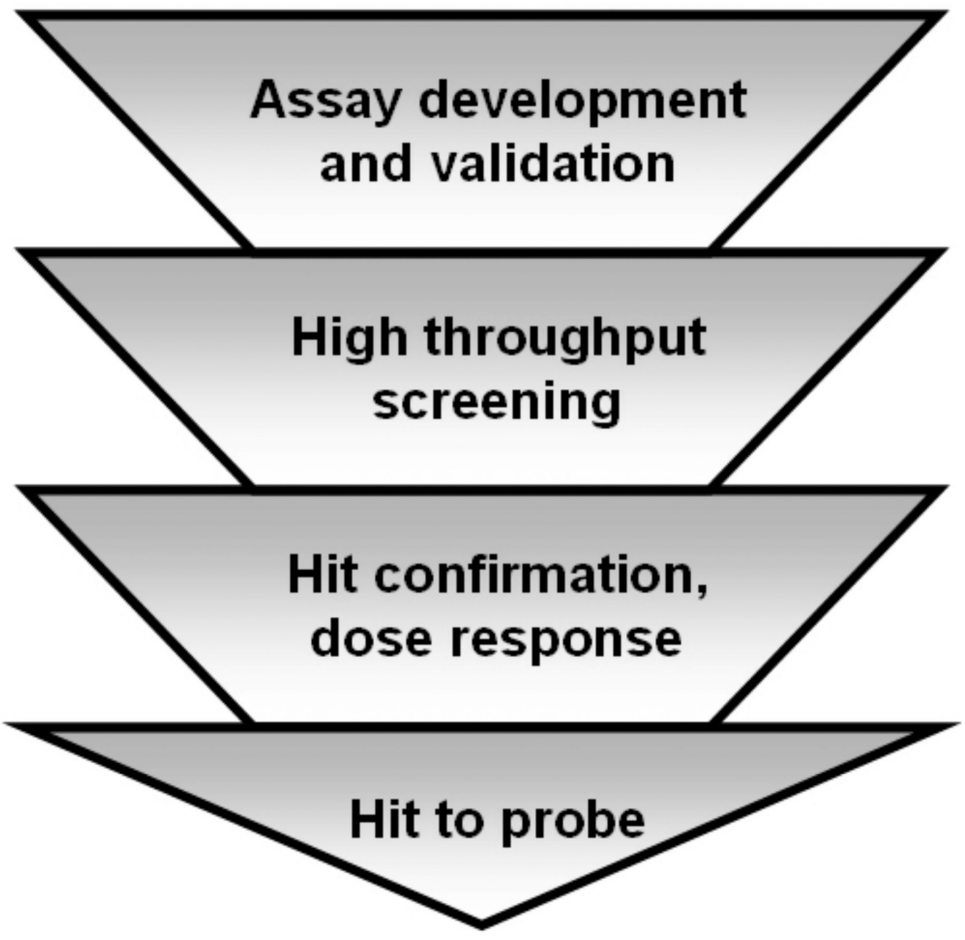

Fig. (1).

Drug discovery project progression from basic research to probe development. 


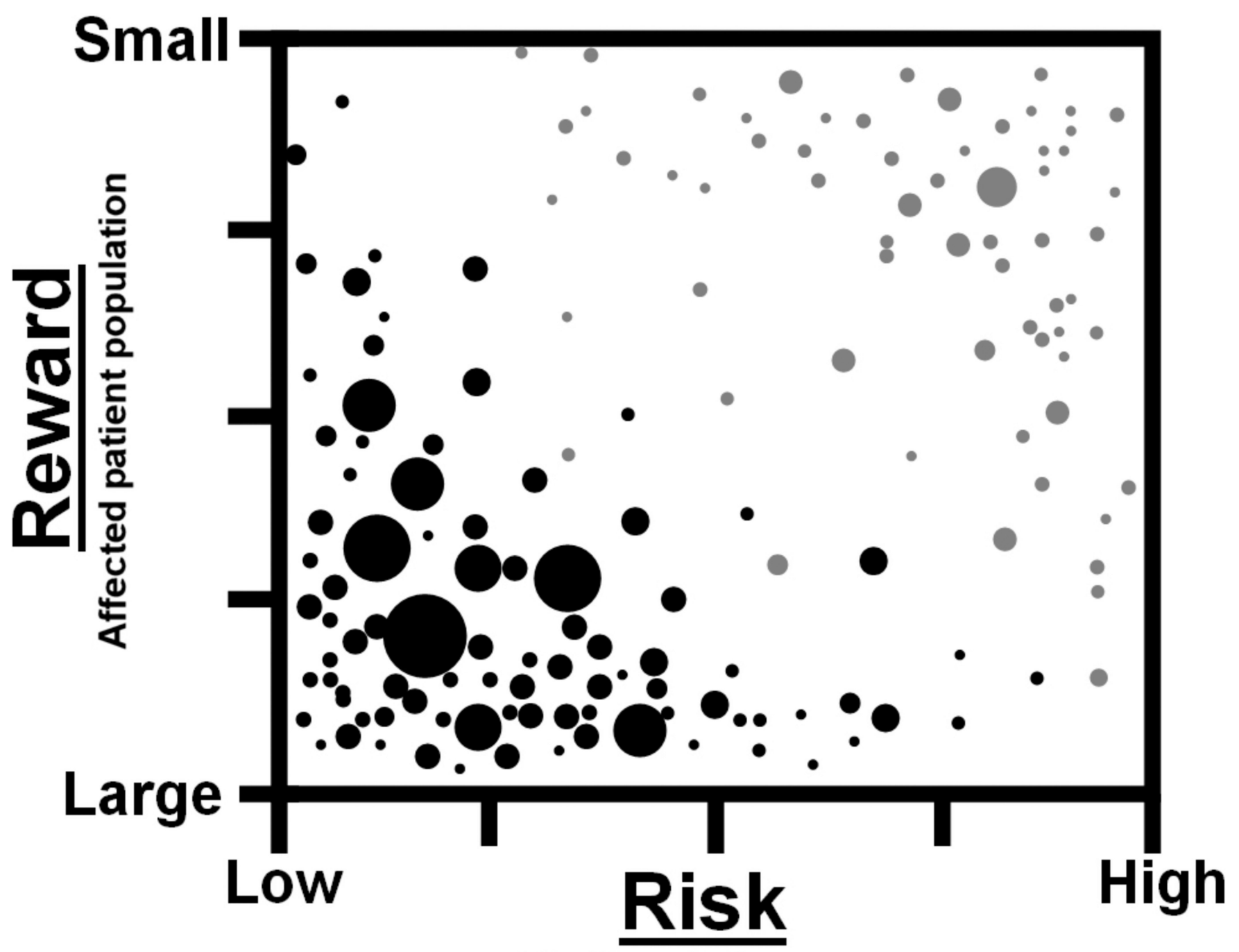

\section{Likelihood of success}

Fig. (2).

Generalization of Academia vs. Industry in terms of (1) risk tolerance vs. (2) affected patient population. Each dot represents an HTS campaign. This is a hypothetical generalization of the relationship between risk and reward against investment, not based on actual data. Black dot $=$ Private domain HTS, Grey dot $=$ Public domain HTS. Size of dot $=$ Dollars spent or resources allocated on a project. 
Technology

Development

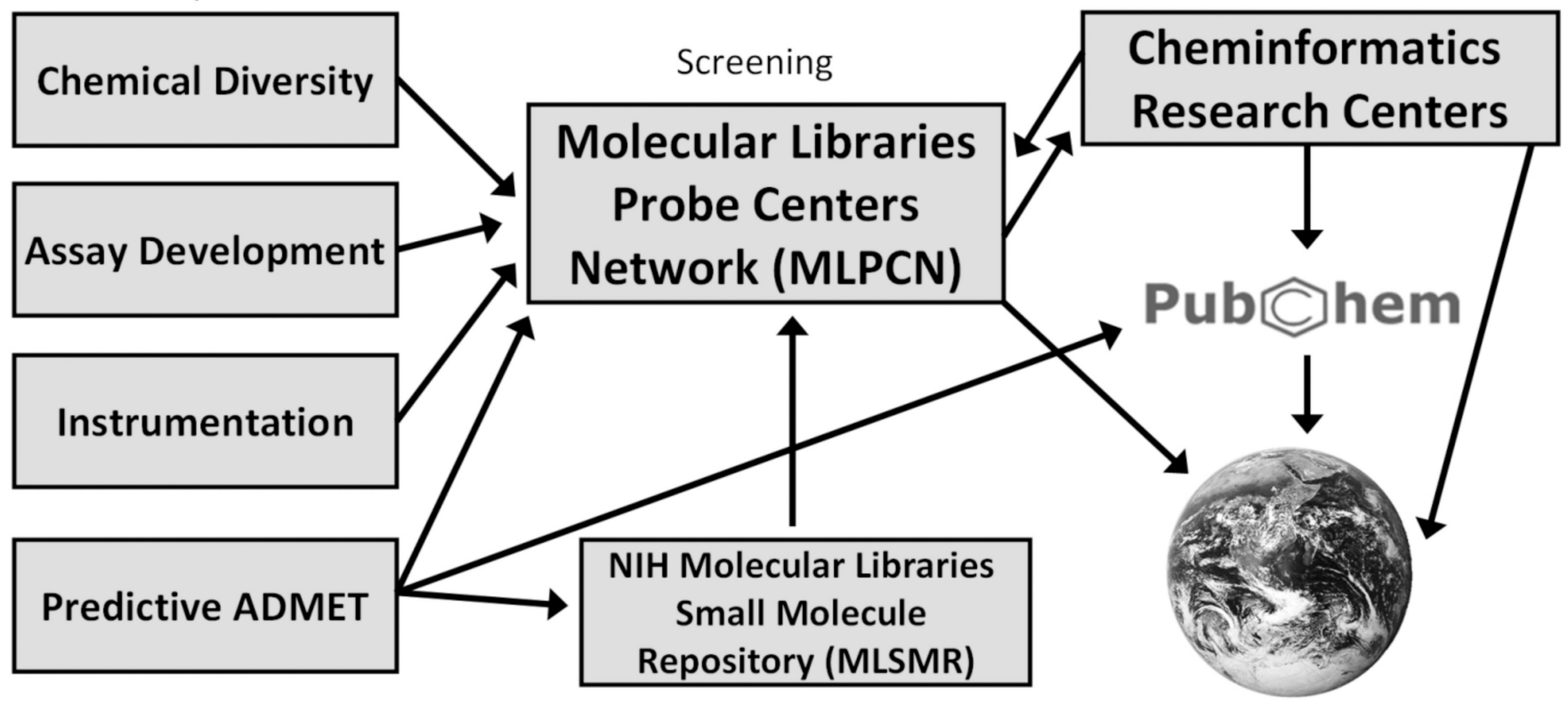

Fig. (3).

Industry level drug discovery in the public domain. The Molecular Libraries Probe Centers Network (MLPCN) has brought together critical facets of the drug discovery process to the public, giving open access to comprehensive compound screening and probe development, advancing research through public data sharing via Pubchem. 

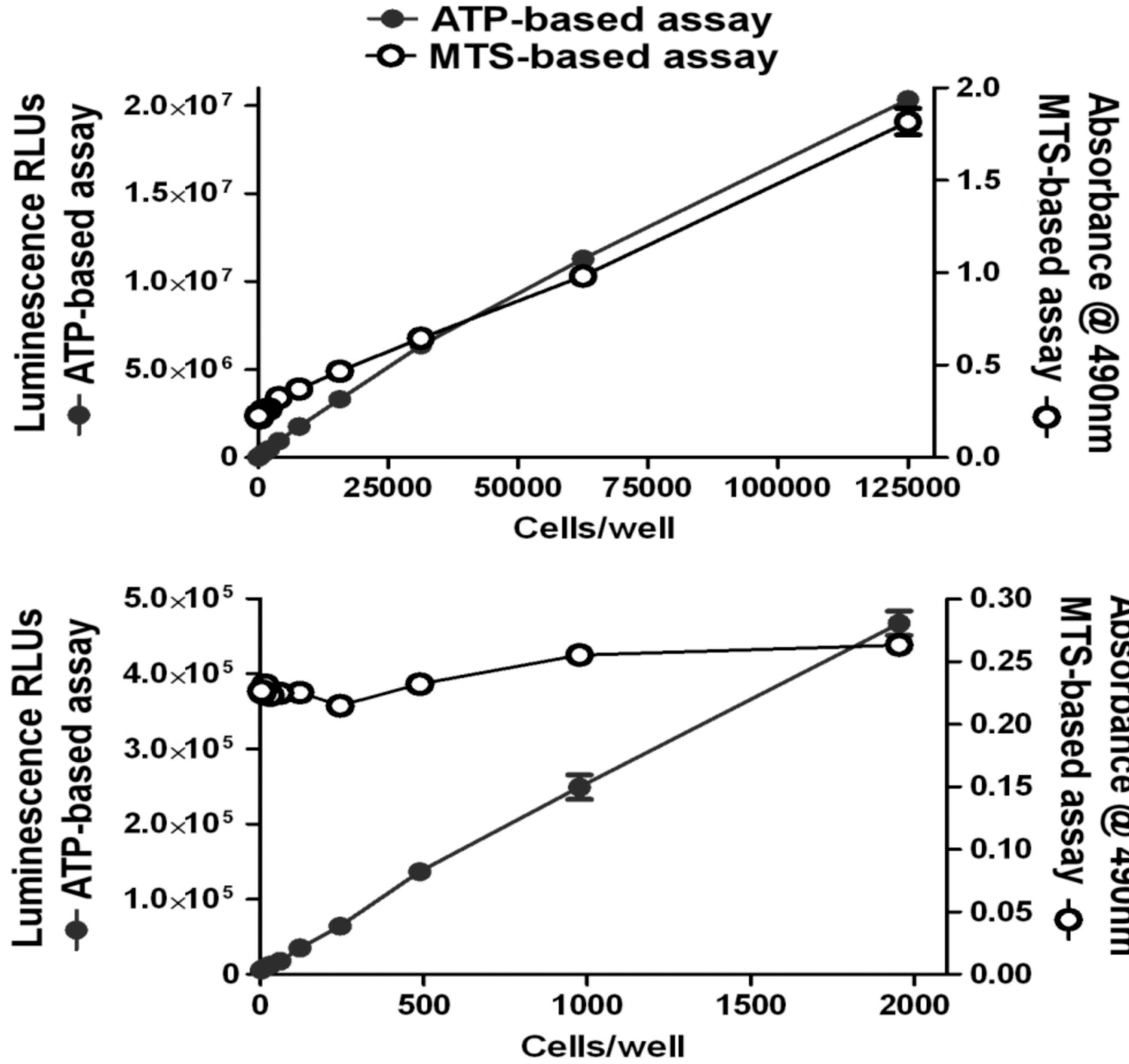

Fig. (4).

Example assay comparison for determining assay sensitivity for high throughput screening (HTS), Tetrazolium-based MTS versus ATP quantitation of cell viability. Breast adenocarcinoma cells (MCF-7 derivative) were seeded at a range of 4-125,000 cells per well, followed by cell viability assessment by MTS and ATP quantitation assays. The characteristics of the homogenous ATP-based assay were superior to the MTS assay, and the improved sensitivity for measuring low numbers of cells (below 2,000 cells/well) confirmed that the ATP-based assay method was more suitable for HTS. 
Table 1

The Molecular Libraries Probe Production Centers Network (MLPCN)

\begin{tabular}{|c|c|c|c|}
\hline MLPCN Center & Director & Function & Services \\
\hline $\begin{array}{l}\text { Broad Institute of MIT and } \\
\text { Harvard }\end{array}$ & Stuart Schreiber & \multirow{4}{*}{ Comprehensive Centers } & \multirow{4}{*}{$\begin{array}{l}\text { Provide services covering ssays, cheminformatics/ } \\
\text { informatics, and medicinal chemistry. }\end{array}$} \\
\hline Sanford/Burnham Institute & John Reed & & \\
\hline NIH Chemical Genomics Center & Chris Austin & & \\
\hline Scripps Research Institute & Hugh Rosen & & \\
\hline Johns Hopkins & $\operatorname{Min} \mathrm{Li}$ & \multirow{3}{*}{ Specialized Screening Centers } & \multirow{3}{*}{$\begin{array}{l}\text { Handle specialized types of assays including } \\
\text { handling assay informatics. }\end{array}$} \\
\hline Southern Research Institute & Colleen Jonsson & & \\
\hline University of New Mexico & Larry Sklar & & \\
\hline University of Kansas & Jeffrey Aube & \multirow{3}{*}{ Specialized Chemistry Centers } & \multirow{3}{*}{$\begin{array}{l}\text { Focus on providing medicinal chemistry and } \\
\text { cheminformatics support for performing structure- } \\
\text { activity relationships that is typically needed to } \\
\text { produce useful chemical probes from screening hits. }\end{array}$} \\
\hline Vanderbilt University & Craig Lindsley & & \\
\hline & & & \\
\hline
\end{tabular}

The most prominent public domain HTS resource of the past decade was the Molecular Libraries Screening Centers Network (MLSCN) and its successor, the Molecular Libraries Probe Production Centers Network (MLPCN). The MLSCN was a national high-throughput biological screening resource that was launched on June 15, 2005, and operated as a pilot phase for three years, replaced in June 2008 by the MLPCN. While the MLSCN consisted of ten similar screening centers, the MLPCN is composed of three different types of centers: comprehensive centers, specialized screening centers, and specialized chemistry centers. 
Table 2

\section{The Critical Path of MLPCN Screening}

\begin{tabular}{|c|c|c|}
\hline Step & Requirement or Cutoff & Location \\
\hline Assay development \& validation & Reproducible assay & Assay Principal Investigator \\
\hline Application to MLPCN & Valuable/novel target & Assay Principal Investigator \\
\hline Primary assay (HTS) & $<10 \mu \mathrm{M}$ & MLPCN Screening Center \\
\hline Secondary Assay/Dose Response & IC50<1 $\mu \mathrm{M}$ & MLPCN Screening Center \\
\hline Counterscreen assay & Selectivity $>30 \times$ & Assay Principal Investigator \\
\hline Chemistry/SAR & Best probe & Specialized Chemistry Center or Comprehensive Screening Center \\
\hline
\end{tabular}

The progress of an assay to and through the MLPCN follows a critical path of steps containing cutoffs for potency, dose response, and selectivity. Following the basic research efforts of a principle investigator (PI), an assay is developed to assay a novel or interesting target [8]. The PI applies to have the assay adapted to a high throughput screen through an MLPCN funding mechanism. If the assay and/or target are novel, interesting, and amenable to HTS, the MLPCN will import the assay to one of the production phase MLPCN screening centers. . The primary assay will then be performed at the MLPCN screening center, testing anywhere from 50,000 to 500,000 small molecules in the MLPCN compound library at $10 \mu \mathrm{M}$ to identify active compounds (actives).. These actives are then subjected to secondary screening, where they are tested at a range of four log concentrations, to confirm the active and to identify an IC50 for the compound in the assay. Compounds with submicromolar IC50s $(<1 \mu \mathrm{M})$ proceed to counter screening and further development into a probe. Data is shared with the public through PubChem. 


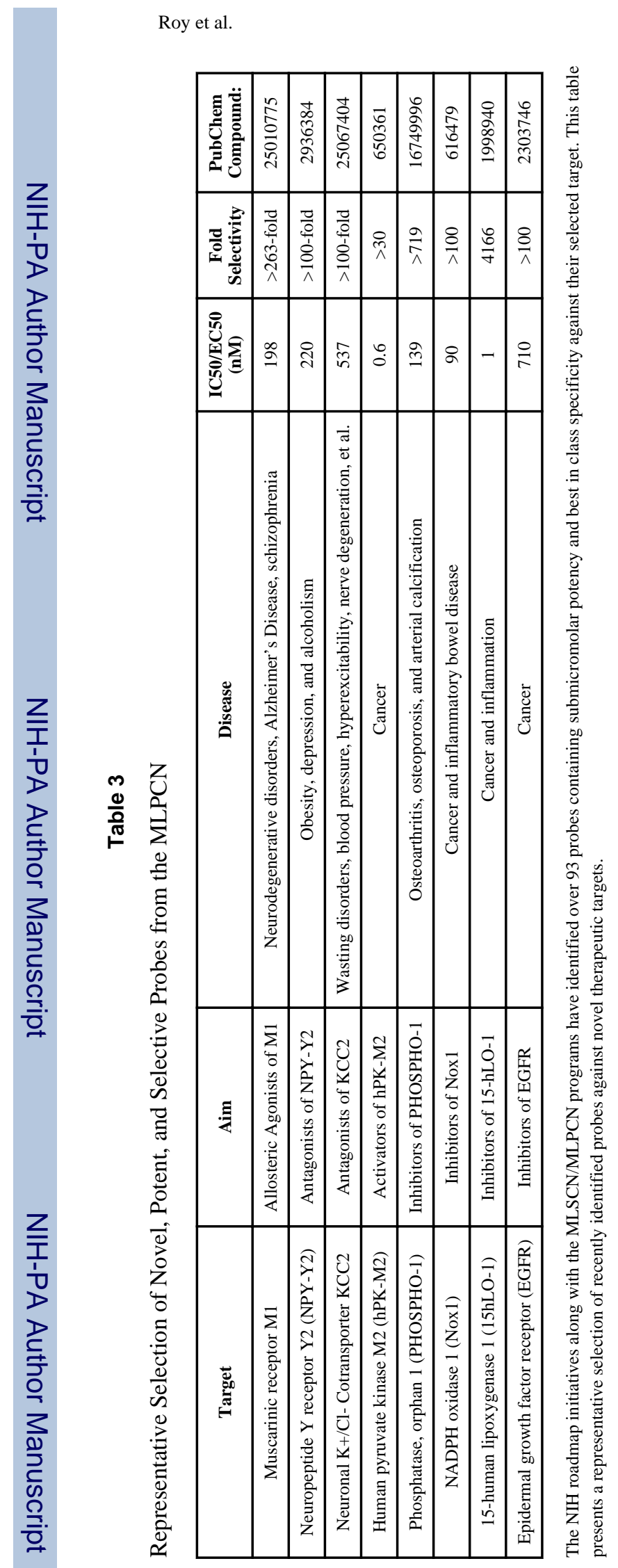

Page 25 
Table 4

Academic High Throughput Screening Centers

\begin{tabular}{|c|c|c|c|}
\hline Institution & Chemical Library Size & Director/Contact & Website \\
\hline Havard Medical School & $101-150 \mathrm{~K}$ & Marcie Glicksman & www.hcnr.med.harvard.edu/ \\
\hline Broad Institute of MIT and Harvard & 500,000 & Michael Foley & www.broad.mit.edu/node/139 \\
\hline Columbia University Medical Center & 118,000 & James Rothman & www.columbia.edu \\
\hline Emory University & 200,000 & Haian Fu & www.pharm.emory.edu \\
\hline Harvard Medical School & 250,000 & Caroline Shamu & iccb.med.harvard.edu \\
\hline Johns Hopkins University & 180,000 & Min Li & www.hopkinschemcore.org \\
\hline National Cancer Institute & $101-150 \mathrm{~K}$ & James McMahon & home.ncifcrf.gov/mtdp/index \\
\hline NIH Chemical Genomics Center & 500,000 & Jim Inglese & www.ncgc.nih.gov \\
\hline Ordway Research Institute & $101-150 \mathrm{~K}$ & Graham Brock & www.ordwayresearch.org/target \\
\hline Sanford/Burnham Institute & 500,000 & John Reed & bccg.burnham.org \\
\hline Scripps Research Institute & 500,000 & Peter Hodder & mlpcn.florida.scripps.edu \\
\hline Southern Research Institute & 500,000 & Lucille White & www.southernresearch.org/research/hts-center \\
\hline St Jude Children's Research Hospital & 500,000 & Taosheng Chen & www.stjude.org \\
\hline Stanford University & 130,000 & David Solow-Cordero & htbc.stanford.edu \\
\hline University of Cincinnati & 250,000 & Ruben Papoian & www.drugdiscovery.uc.edu \\
\hline University of Illinois & 200,000 & Chen Zhang & www.scs.uiuc.edu/htsf \\
\hline University of Kansas & 171,736 & Rathnam Chagaturu & www.hts.ku.edu \\
\hline University of New Mexico & 231,000 & Larry Sklar & nmmlsc.health.unm.edu \\
\hline University of Pennsylvania & 218,000 & Scott Diamond & www.seas.upenn.edu/ pcmd/hts \\
\hline University of Pittsburgh & 300,000 & John Lazo & www.upddi.pitt.edu \\
\hline University of Washington & $101-150 \mathrm{~K}$ & Timothy Martins & depts.washington.edu/uwhts/ \\
\hline University of Wisconsin Madison & 105,000 & F. Michael Hoffmann & www.hts.wisc.edu \\
\hline UT Southwestern Medical Center & 200,000 & Michael Roth & www.utsouthwestern.edu \\
\hline Vanderbilt University & 260,000 & David Weaver & www.mc.vanderbilt.edu/centers/mlpcn/index \\
\hline Walter \& Eliza Hall Institute & $101-150 \mathrm{~K}$ & John Parisot & www.biotechcentre.net.au/HTCS/htcs \\
\hline Washington University & 140,000 & Jayne Marasa & mic.wustl.edu/Cores/HighThroughputCore \\
\hline
\end{tabular}

The past decade has seen a rise in the number and size of academic HTS centers, containing large compound libraries of 100,000 or more compounds. 
Table 5

Common Assay Methodologies for HTS in The Public Domain

\begin{tabular}{|c|c|c|c|}
\hline Screen & Assay readout & Summary & Example application \\
\hline \multirow{3}{*}{ Biochemical } & FP & $\begin{array}{l}\text { Fluorescence polarization, ratiometric readout of } \\
\text { polarized light alteration. }\end{array}$ & Receptor-ligand interactions \\
\hline & FRET & Fluorescence resonance energy transfer. & Kinase activity measurement \\
\hline & TR-FRET & $\begin{array}{l}\text { Time-resolved fluorescence resonance energy } \\
\text { transfer. }\end{array}$ & Kinase activity measurement \\
\hline \multirow{3}{*}{ Cell based } & RNA interference & $\begin{array}{l}\text { Small interfering RNA (siRNA) mediated } \\
\text { silencing of genes. }\end{array}$ & Genome siRNA library \\
\hline & High content analysis & $\begin{array}{l}\text { Quantification of protein location and } \\
\text { expression by microscopy-based imaging. }\end{array}$ & Fluorescently labeled antibodies \\
\hline & Fluorescence - kinetic & $\begin{array}{l}\text { Rapid detection of fluorescence from calcium- } \\
\text { or voltage-sensitive dyes (FLIPR). }\end{array}$ & $\begin{array}{l}\text { G-protein coupled receptor, ion } \\
\text { channels }\end{array}$ \\
\hline \multirow{3}{*}{ Label free } & Optical biosensors & $\begin{array}{l}\text { Detection of phenotypic cellular changes, and } \\
\text { binding events between compounds and } \\
\text { biomolecular targets. }\end{array}$ & $\begin{array}{l}\text { G-protein coupled receptor } \\
\text { activation }\end{array}$ \\
\hline & Resonant Acoustic Profiling & $\begin{array}{l}\text { Real-time detection of specificity, affinity, } \\
\text { kinetics, and concentration of molecular binding } \\
\text { interactions. }\end{array}$ & Molecular binding events \\
\hline & $\begin{array}{l}\text { Surface plasmon resonance } \\
\text { (SPR) }\end{array}$ & $\begin{array}{l}\text { Measurement of protein-protein interaction and } \\
\text { binding affinity by changes in refraction and } \\
\text { resonance. }\end{array}$ & $\begin{array}{l}\text { G-protein coupled receptor } \\
\text { activation }\end{array}$ \\
\hline \multirow{5}{*}{$\begin{array}{l}\text { Cell based or } \\
\text { Biochemical }\end{array}$} & Bioluminescence & $\begin{array}{l}\text { Detection of bioluminescence by reporter gene } \\
\text { assays. }\end{array}$ & Luciferase detection \\
\hline & ECL & Electrochemiluminescence assay. & ELISA based assays \\
\hline & Fluorescence - chromophores & $\begin{array}{l}\text { Detection of flurescent probes and antibodies } \\
\text { binding to cellular components. }\end{array}$ & Alexafluor detection \\
\hline & Fluorescence - proteins & $\begin{array}{l}\text { Fluorescing protein detection from reporter gene } \\
\text { assays \& protein-protein interactions. }\end{array}$ & $\begin{array}{l}\text { Green fluorescent protein (GFP) } \\
\text { detection }\end{array}$ \\
\hline & PCA & $\begin{array}{l}\text { Protein complementation assay, detects } \\
\text { interacting proteins. }\end{array}$ & Luciferase, B-lactamase, GFP \\
\hline
\end{tabular}

Academic and government HTS centers have many of the same capabilities and technologies as the pharmaceutical industry, enabling equal capacity for primary, secondary and tertiary screening, covering a wide range of assay methodologies, ranging from conventional biochemical and cell-based assays to novel label-free high throughput methods. 
Table 6

Characteristics of an Ideal Probe *

\begin{tabular}{|c|l|}
\hline \multirow{4}{*}{ Parameter } & Characteristic Feature \\
\hline \multirow{4}{*}{ Chemistry } & Proven chemical identity with a defined structure \\
\cline { 2 - 3 } & $\begin{array}{l}\text { Close analogs with a clear and quantifiable structure-activity relationship over a 2-3 log drug } \\
\text { concentration range }\end{array}$ \\
\cline { 2 - 3 } & More than one chemotype with an analogous activity profile \\
\hline \multirow{5}{*}{ Efficacy and Potency } & Biochemical target specificity or -selectivity around 3 orders of magnitude, within class \\
\cline { 2 - 3 } & $\begin{array}{l}\text { Pharmacological profile against targets within class and across related biochemical classes to be 2-3 } \\
\text { orders of magnitude lower }\end{array}$ \\
\cline { 2 - 3 } & Clear sigmoidal dose-activity relationship \\
\cline { 2 - 3 } & Maximal efficacy within 2 log concentration range \\
\cline { 2 - 3 } & Potency at submicromolar (biochemical) or micromolar (cellular) level \\
\cline { 2 - 3 } & Target selectivity established within the cellular context \\
\cline { 2 - 3 } & Mechanism of action defined and established without ambiguity \\
\hline \multirow{2}{*}{$\begin{array}{c}\text { Pharmacokinetic and } \\
\text { pharmacodynamic properties }\end{array}$} & $\begin{array}{l}\text { Preferred, but not necessary, ADMET profile, adherence to Lipinski rules, membrane permeability, } \\
\text { aqueous solubility, etc. }\end{array}$ \\
\hline Intellectual property rights & Preferred, but not necessary \\
\hline
\end{tabular}

The characteristics of a successful lead are distinctly different from the ones defined here for a chemical probe. Medicinal chemistry optimization of a probe meeting the criteria listed here should result in the development of lead(s) with ideal PK/PD properties and clear IP rights that are paramount for a lead with tractable chemistry. 
Table 7

Pharmaceutical Collaborations and Research Extensions

\begin{tabular}{|c|c|}
\hline Pharma & R\&D Units \\
\hline Novartis & Institutes of Biomedical Research \\
\hline GSK & Centers of Excellence for Drug Discovery \\
\hline Pfizer & Bio-therapeutics and Bio-Innovation Center \\
\hline Pfizer & CTSA Pharmaceutical Assets portal \\
\hline Eli lilly & Phenotypic Drug Discovery (PD2) Initiative \\
\hline Merck & Merck-Sage Bionetworks \\
\hline Novartis-MIT & Center for Continuous Manufacturing \\
\hline Lilly-Melbourne & Lilly-Melbourne Academic Psychiatry Initiative \\
\hline Merck & External Basic Research \\
\hline
\end{tabular}




\section{Table 8}

Roadmap for Successful High Throughput Screening

- The Entire Target Universe is at Academia's Doorstep to Explore, Conquer and Eradicate Diseases Afflicting Humanity. For this to happen-

- Continue strong therapeutic biology focus

- In-depth biology is academia's GREATEST strength

- Establish a state-of-the art screening facility with pharma trained personnel

- Maintain a high 'quality' \& 'diverse' chemical library, and expand based on project scope

- Cell lines- bring them fresh from a commercial source

- Use cutting edge tools and technology formats

- Make medicinal chemistry involvement a prerequisite

- Manage IP issues with appropriate balance between public sharing and commercial exploitation

- $\quad$ Establish secondary and tertiary assays to determine selectivity and specificity

- Encourage collaborative interactions to drive probe discovery

- Actively manage projects, a pharma best practice, with trained project coordinators, with clear goals, timelines and go/no-go criteria

- Make the Principal Investigator in the driver's seat

- $\quad$ Engage in training the next generation of scientists 